\title{
The Question Board
}

\author{
By Donna Pittman
}

Assistant Undergraduate Librarian

University of Illinois at Urbana-Champaign

\section{An anonymous, short-answer reference service in an academic library.}

$\mathbf{W}_{\mathrm{b}}$ hy do women shave their legs?" "How are marshmallows made?" "Where is Ethel Merman buried?" Who would be daring enough to approach a reference librarian in an academic library with any one of these queries? Should academic reference librarians worry about those less than daring individuals with curiosities about not quite academic subjects? No doubt most librarians have enough to do without tracking down answers to questions about Ethel Merman and marshmallows. Would sober-minded professionals actually encourage such questions? Why would they do such a thing?

Librarians at the University of Illinois Undergraduate Library did just that when they created the "Question Board" as an extension of the reference desk, providing an outlet for those patrons with questions about things that nearly everyone wonders about but may be afraid to ask.

\section{How it works}

The Question Board is an anonymous shortanswer reference service that, in contrast to the traditional reference desk, is an $8 \times 10$-foot section of wall that has been covered with particle board and burlap. Library users, predominantly undergraduate students, write questions on slips of paper and drop them into a box attached to the Board. Librarians and graduate assistants research the information requested and post the answer attached to the original question for all to read. The answer in- cludes the source or sources where the information was located, the initials of the person who answered the question, and the date. The service allows the patron to remain anonymous and eliminates face to face interaction with a librarian, since all interactions are on paper.

Since its inception in the early 1970s the Question Board has been popular with students and other patrons of the library, perhaps because it provides an alternative to approaching a reference librarian with queries a patron might feel are too insignificant or unimportant or embarrassing to ask. The risks of "bothering" a librarian at the reference desk, showing one's ignorance, or asking a question that might elicit a funny look from the librarian are all eliminated for the patron. Some 600 to 700 questions per semester are submitted to the Question Board, an average of about 160 questions per month, or about one-tenth the number asked at the reference desk each month.

While information sought at the reference desk frequently pertains to topics selected for term papers or course assignments, use of the card and online catalogs, and the location of books or other materials in the library, questions posed to the Question Board run the gamut of human curiosity, from requests for sports statistics to queries about the nature of love. Questions of a personal nature are asked of the Question Board that are rarely, if ever, asked of reference librarians, such as, "If I seek drug or alcohol counseling at the student health center, will this go on my university rec- 
ord?" Or "What should I do if I am failing a course?" A sizable portion of questions (nearly $10 \%$ last semester) seek addresses, from Cyndi Lauper to the CIA. Many queries, nearly $25 \%$, pertain to the campus and its history, from questions about the school's colors to the ratio of men to women in the freshman class. Frequently questions are about the library itself, such as "Why is it so hot (or cold) in here?" "Where is the fiction?" and "What can be done about the noise in here?"

The Board is divided rather arbitrarily into seven broad categories under which answers are sorted when posted. These categories change from time to time, the latest being Sports, Entertainment, Science and Nature, Addresses, Campus and Community, Library, and General. Answers to questions are typed on colored slips of paper. Every two weeks the Board is cleared of old questions and answers, and new ones with paper of a different color are affixed, thereby alerting Question Board followers that new questions and answers have been posted. Old questions are saved for the duration of the semester, counted and then destroyed unless they are questions likely to be asked again. Those are filed for future reference. Questions which prove difficult or impossible to answer are posted with an explanation of how the answer was researched, perhaps a request for more information, or a referral to the reference desk. In certain instances, phone numbers or addresses are given with suggestions of how the patron might proceed on his or her own if the information called for is not within the scope of the library's collection.

\section{Why it works}

While the great majority of questions are sincerely asked and are conscientiously researched by the staff, some are clearly posed in a humorous vein, such as the question, "How much dirty laundry will a 1980 Chevette hold?" submitted shortly before Thanksgiving break. Both types of questions afford library staff members the opportunity to communicate with library users in a unique way. Staff members provide answers to questions for all to see and read and can add a touch of geniality or humor in their manner of answering. The process provides an uncommon channel of exchange between library staff and users, valuable to both. In an article entitled, "Information Needs of Human Beings," Yates lists four basic needs of individuals met by libraries, one of which is diversion, "the search for an escape from the monotony, physical and mental exhaustion, frustration, confusion, conflict, failure, and disappointment of the working-day world." For university students whose work is never done until the semester ends, the need for diversion is clearly evident and is reflected in the popularity of the Question Board,

\footnotetext{
${ }^{1}$ Brian Yates, "Information Needs of Human Beings," International Forum of Information and Documentation 9 (January 1984):24-28.
}

from the hundreds of queries submitted each semester to the number of students who can be continually observed perusing the Board.

This service also answers a need of a different type, the need of the library user to request information in the most non-threatening way possible, so that he or she doesn't decide that getting the information is not worth the process required to obtain it. In a study of university students, Swope and Katzer found that a majority of students did not make use of the reference services of the library because they did not want to "bother" the librarian, they felt their question was too simple, and they did not want to appear stupid. ${ }^{2}$ Lederman focused on "communication apprehension" or a fear of talking with another individual as a possible factor which inhibits some library users from seeking the assistance of a reference librarian. ${ }^{3}$ Other authors have speculated that the reference desk itself is a barrier to communication, distancing the patron from the professional. ${ }^{4}$ Whatever the reasons, it does seem apparent, both from the literature and from observation, that there are library users who are reticent to ask for help in finding information or finding their way around the library. By providing a reference service which allows patrons to ask any question, anonymously, no matter how seemingly trivial, the library conveys a message to the patron which says, "Ask questions-no question is too small, too silly, too bothersome to answer." The public relations benefit this service affords the library has been continually evident, from newspaper articles featuring the Question Board to the calls and letters from alumni and others who remember or have heard about this service. Many request information that they have been unable to locate, indicating that the Question Board is their last resort.

Another way in which this service functions as a public relations tool is that it allows staff members to communicate with patrons about matters concerning the library and its operation. A considerable number of questions submitted to the Question Board are about the library, from inquiries about temperature fluctuations in the building to online catalog downtime. By responding to these kinds of inquiries the Question Board staff is able to provide information regarding library practices, policies and problems to many patrons at one time. It can only benefit public relations to let irritated patrons know that the staff is indeed aware that the library is too cold and that steps are being taken to remedy the situation.

\footnotetext{
${ }^{2}$ Mary Jane Swope and Jeffrey Katzer, "The Silent Majority: Why They Don't Ask Questions," $R Q 12$ (Winter 1972):161-66.

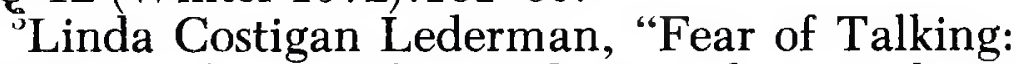
Which Students in the Academic Library Ask Librarians for Help?" RQ 20 (Summer 1981):382-93.

${ }^{4}$ Larry Larason and Judith Scheik Robinson, "The Reference Desk: Service Point or Barrier?" $R Q 23$ (Spring 1984):332-38.
} 


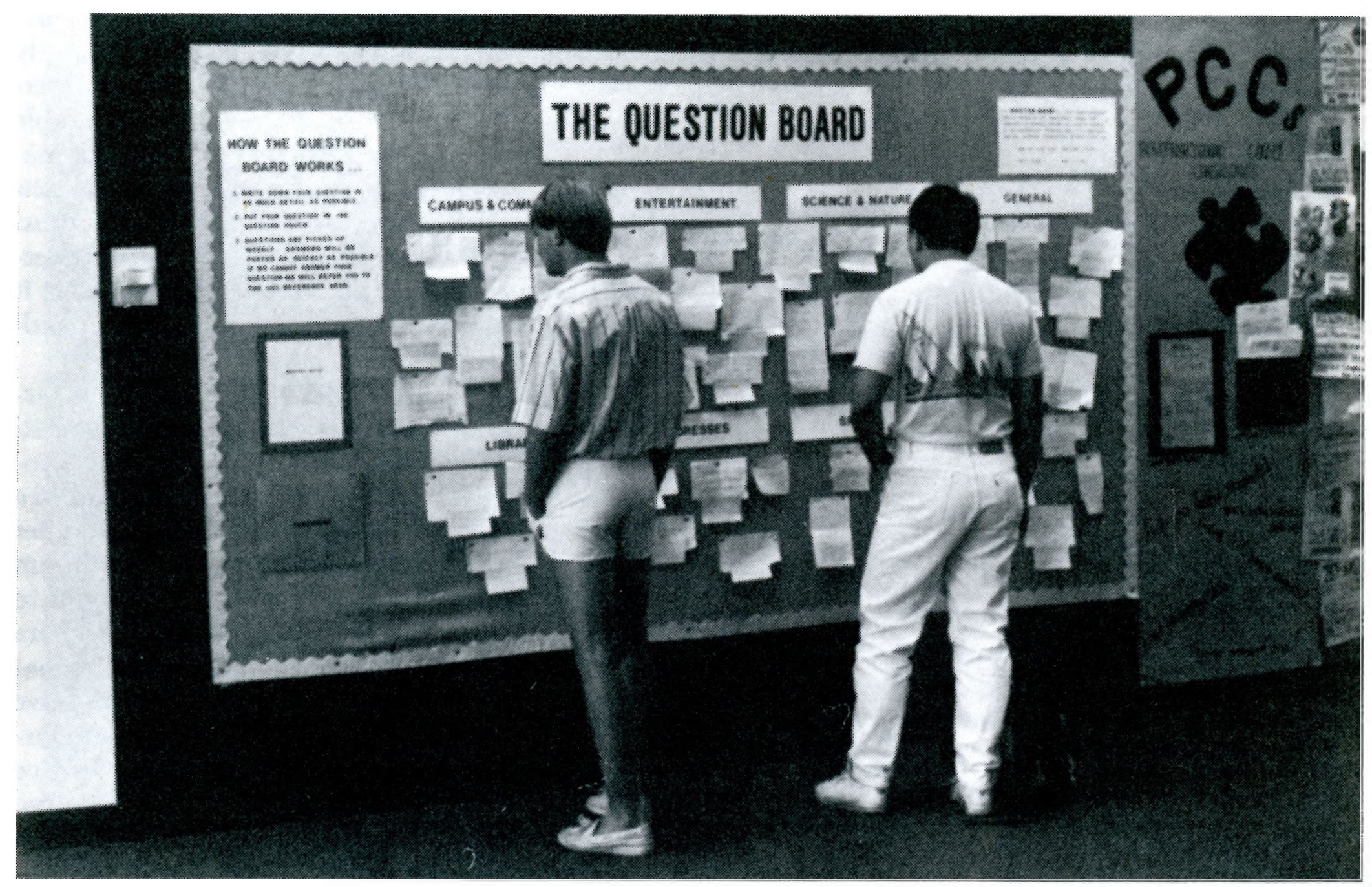

Students seek diversion as well as information at the UIUC Question Board.

\section{The boot camp of reference service}

In addition to providing library patrons with a place to ask any question anonymously, the Question Board also provides an excellent training ground for reference staff. The Undergraduate Library employs students from the University of Illinois' Graduate School of Library and Information Science who assist the librarians in a variety of tasks, including supervision of the circulation desk, cataloging, bibiliographic instruction, and reference service. Because of the many duties graduate assistants are expected to perform, training at the beginning of the fall semester, when most begin work at the library, can be hectic and difficult, both for the students and the librarians. Incoming graduate assistants, usually new to the campus and the library, must learn a great deal in a short time about the various roles they are expected to fulfill, while librarians must orient the newcomers during the busiest time of the academic year. Because working on the Question Board allows graduate assistants a gradual transition into work at the reference desk, the Question Board has functioned as a kind of "boot camp" for reference service.

Graduate assistants begin training by working on questions submitted to the Board, enabling them to become familiar with the reference collection and individual reference tools without the pressure of a patron looking over their shoulder. The "trainees" are able to search for information at their own pace and to consult with reference librarians when necessary. Prior to searching for answers to questions, graduate assistants meet with a librarian who supervises the Question Board and are given a number of handouts consisting of an outline of the procedure, a guide to searching various types of questions, including names of reference tools and subject experts within the library, and a bibliography of commonly-used sources. After spending at least ten hours working on the Question Board, each graduate assistant works with a librarian at the reference desk for approximately five hours. Once both phases of training are complete, graduate assistants are well prepared to assist and substitute for librarians at the reference desk.

\section{Any drawbacks? A good question}

There are limitations to this type of reference service. One drawback is that questions are not answered instantly and, in order to prevent library users from believing that their question will be answered immediately, a sign is posted on the Board encouraging those who need information right away to visit or phone the reference desk.

A second limitation, inherent to this type of reference service, is the elimination of the reference interview. Library users do not have the opportunity to clarify, interpret or modify their requests in consultation with a librarian. Of course, that may be what they are actually trying to avoid when they approach the Question Board with their questions. Staff members must take the written question at face value and attempt to provide the information requested. However, if more information or clarification is needed, the question is put on the Board with a request for such.

Third, this service is also limited to questions 


\section{Why we arrange books as we do}

\section{By Constance A. Mellon East Carolina University}

"Why must we do these things just so?" Young catalogers want to know.

"There are good reasons," I reply.

"So listen, and I'll tell you why."

Old Melvil Dewey, clever lad,

Once said, "The state of things is bad.

There is no order to the way

That books are shelved. I'll start today."

And after days of thought and toil,

And nights of burning midnight oil,

He cried, "Oh yes! I've got it now!

It's easy. Let me show you how.

You take nine hundred ninety-nine,

Then break it down. This plan of mine

Will revolutionize our work."

Then Melvil, never one to shirk,

Created, in a careful frame,

The system that still bears his name.

But LC kept collecting books.

They sat on shelves. They hung on hooks.

They covered tables, chairs, the floor-

Arranging them was quite a bore.

So LC said, "I guess it's true.

Nine hundred ninety-nine won't do.

These categories cannot grow

As we expand the things we know.

Though once the decimal was fine,

The numbers can't fit on the spine.

It's all those numbers-that's the worst.

So let's use letters. They'll come first.

We'll use this way in every college

To classify the world of knowledge."

Said OCLC, "Hold the phone!

Why do we always work alone?

We work through winters, summers, springs,

To catalog the same darn things.

And though we're working day and night,

Our backlogs still are out of sight.

If we could just communicate,

Then we could all stop working late.

And, since we have computers now,

Let's work together. Here is how:

We'll catalog from east to west,

From north to south. It's really best

To let us guide you." So they did.

We still are doing as they bid.

"And so you see, there is no mystery.

It's simply cataloging history." calling for single fact information or short answers. It is a type of ready reference which doesn't strictly adhere to the definition of ready or quick reference. Some questions are not readily answerable and must be researched extensively, and the patrons don't receive a quick answer in the sense that they receive the answer immediately...they must wait for the answer to be posted. Since new questions and answers are posted every two weeks, it could be a wait of two days or two weeks depending on when the question was submitted.

Finally, despite everyone's best efforts, it is virtually impossible to answer every question submitted. As one staff member put it, "The more we answer, the more they ask." Graduate assistants and a librarian spend a combined total of thirty hours per week answering questions, probably the maximum number of hours this library can afford to devote to the service at this time. In order to alert users there is a sign posted on the Board which explains that due to the number of questions received we have been unable to answer every question, and encourages use of the services available at the reference desk should the answer not appear within two weeks time. It may be worth noting that our goal is to answer or at least respond to every question submitted.

\section{Conclusion}

It is apparent that students and other users of the library prize this service that has become something of an institution since its inception in the early 1970s. One can observe students continually perusing the Board. The campus newspaper has featured the Question Board in a number of articles; at one time it ran a series featuring interesting questions answered each week on the Board. Students often write their own comments or suggestions on posted questions and answers. As one patron, a visiting public librarian, noted, "The questions and answers are interesting, but it is the interaction between staff and students and among students themselves that is especially appealing." Perhaps because of the anonymity, the interaction - like the questions - tends to be lively and uninhibited. Students don't hesitate to critique or expand on answers or give their own suggestions. It may be this aspect more than any other that library users find the most captivating. While not a service which is typical of academic libraries, it has proven to fit in well in the academic setting, especially in a library designed for and used primarily by undergraduates. Despite its limitations, provision of this service in conjunction with conventional reference service meets a broader spectrum of needs than would the reference desk alone. The Question Board provides students with a place to ask silly, curious, trivial, consuming, nagging, important questions... and provides the answers as well. 